\title{
Entre páginas de libros antiguos: la descripción bibliográfica mate- rial en México
}

\author{
Idalia García *
}

Artículo recibido:

3 de agosto de 2005.

Artículo aceptado:

8 de febrero de 2008.

\section{RESUMEN:}

El valor cultural del libro antiguo se refleja en la descripción bibliográfica, la cual es una forma de representar al libro como objeto patrimonial. Sin embargo, dicha tarea debe conocer la naturaleza material y las formas particulares de producción que caracterizan a estos libros. Por ello la representación bibliográfica nos muestra la forma de valorar un libro antiguo y nos acerca a comprender parte de nuestro legado cultural. Este artículo analiza la manera en que las características de la bibliografía material nos ayudan a construir la representación del valor patrimonial, a través de la recuperación de un modelo de descripción bibliográfica que nos permite representar los valores textuales e

* Centro Universitario de Investigaciones Bibliotecológicas de la UNAM, México. pulga@cuib.unam.mx

INVESTIGACIÓN BIBLIOTECOLÓGICA, Vol. 22, Núm. 45, mayo/agosto, 2008, México, ISSN: 0187-358X. pp. 13-40 
históricos de los libros antiguos como instrumento de conocimiento y de control patrimonial.

Palabras claves: Libros Antiguos; Descripción Bibliográfica; Bibliografía material; Patrimonio Documental.

\section{ABSTRACT}

Among pages of rare books: material bibliographical description in Mexico

Idalia García

The cultural value of rare books is reflected in its bibliographical description, which is one way of representing a book as a patrimonial object. However such task requires awareness of the material nature and of the particular forms of production which characterize these books. Thus adequate bibliographical representation is a manner of assessing a rare book and leads us to a better understanding of our cultural legacy.

This paper helps us to comprehend why the characteristics of descriptive bibliography aid to build the representation of patrimonial value through recuperation of a bibliographical description model which allows to delineate the textual and historical values of rare books as instruments of study and patrimonial control.

Keywords: Rare Books; Bibliographical Description; Documental Heritage.

\footnotetext{
"La ignorancia afirma o niega rotundamente; la ciencia duda" Voltaire (1694-1778)
}

\section{INTRODUCCIÓN}

T os libros antiguos conservados en México constituyen una riqueza cultural que lamentablemente no es conocida realmente por la sociedad que los ha heredado, de ahí que no exista una amplia valoración cultural que promueva su adecuada salvaguarda y también su aprovechamiento como recurso del pasado. Una de las razones principales que propicia este desconocimiento y la consecuente falta de valoración, se deriva en parte de la necesaria restricción que establecen las instituciones de custodia para acceder a las 
fuentes originales, condición que también se sostiene por el peculiar interés que ocupan estos objetos en nuestras preocupaciones culturales.

Pero esta preocupación no puede darse de forma espontánea en la sociedad, sino a través de un proceso generacional que se soporte sobre una previa tarea de conocimiento. Tarea que requiere de forma imprescindible de la identificación y construcción de valores culturales, que transmitan los diversos mecanismos institucionales y sociales. En la transmisión es donde resulta crucial la investigación especializada en libros antiguos, y donde se puede apuntalar el reconocimiento social de la riqueza cultural que esos libros representan.

Tal acción es posible a través de la representación bibliográfica del libro antiguo que se realiza en los catálogos institucionales y en repertorios bibliográficos. Ambos instrumentos favorecen tanto el conocimiento especializado como la valoración social de los libros, y permiten también una adecuada transmisión de la fuente original entre las generaciones.

El problema de la representación bibliográfica de un material antiguo ha sido objeto de múltiples reflexiones desde el siglo XIX, cuando se analizaban conceptos, términos y principios, para proponer estándares que posibilitaran la cooperación y el intercambio entre instituciones.

Una de esas propuestas metodológicas que ha probado su función para la valoración patrimonial, el conocimiento especializado y la transmisión de fuentes originales, es la bibliografía material. Dicho conocimiento ha sido recuperado por la catalogación moderna, y se ha enriquecido con las aportaciones de bibliotecarios como personas responsables de la custodia y organización de colecciones bibliográficas antiguas. Este proceso, realizado en todo el mundo, ha definido los estándares internacionales y locales, a través de esfuerzos institucionales (en ocasiones personales) y creado los mecanismos de acceso y control para las colecciones de libros antiguos.

\section{LA TRANSMISIÓN DE BIENES CULTURALES}

La consideración que poseen los libros antiguos como bienes culturales es un aspecto que prácticamente no se discute en ninguna parte. Esta es la que justifica las medidas de protección jurídica, las responsabilidades de las instituciones culturales, las particularidades de conservación, las medidas de restricción de acceso, así como todos los proyectos que se realizan para registrar e identificar las características materiales, tanto textuales como históricas, de los libros antiguos.

De ahí que la representación bibliográfica participe en la custodia de ese patrimonio considerado como una riqueza cultural. Por eso hay que asumir 
tanto la responsabilidad de la salvaguarda de un objeto cultural, como la obligatoriedad de transmitirlo entre las generaciones. Responsabilidad social y cultural que abarca no sólo a los objetos, sino también a los valores y las representaciones que distinguimos en esos bienes.

En México los libros antiguos han estado presentes en las preocupaciones culturales del Estado desde su consolidación a finales del siglo XIX hasta la actualidad. Sin embargo este interés no ha logrado construir una política cultural cuyo resultado sea un pleno y verdadero conocimiento de los libros conservados en todas las instituciones mexicanas, tanto públicas como privadas. En consecuencia parece no reconocerse realmente el valor e importancia que tienen estos libros para nuestra cultura.

Reflejo directo de lo anterior es precisamente la carencia de un catálogo colectivo de impresos antiguos, pese a todos los esfuerzos que se han realizado por conseguirlo. Por otra parte la diversidad metodológica empleada en la descripción de los libros antiguos, nos muestra una valoración cultural escasamente consolidada entre quienes custodian las colecciones institucionales. Extraña condición cultural que podría explicar la situación real que presentan las colecciones de libros antiguos que conservamos en nuestro país. ${ }^{1}$

Por eso la necesidad de distinguir y analizar las formas de representación y valoración que tenemos sobre estos tan particulares objetos heredados del pasado. Consideraremos aquí dos cuestiones importantes. La primera se refiere a la construcción del valor cultural que reconocemos en estos objetos; la segunda, a las formas en que se representa bibliográficamente ese valor para identificar las peculiaridades del objeto custodiado.

Ninguna de estas cuestiones parece tener duda de estar fundamentados en un problema de conocimiento y, que éste es una problemática de la formación profesional. ${ }^{2}$ Pero esta problemática afecta al propio concepto de libro antiguo. En efecto, en otras latitudes, con sus correspondientes desarrollos y aportaciones disciplinares, se ha definido clara y precisamente al libro antiguo para identificarlo como objeto cultural e incluso definirlo como categoría jurídica de protección. Sin embargo en nuestro país esto no ha ocurrido de forma similar, lo que se verá directamente reflejado tanto en las leyes de protección como en el desarrollo de la práctica bibliográfica y catalográfica.

Precisemos lo que entendemos aquí por libros antiguos: los impresos producidos entre 1500 y 1800. Sin embargo debemos distinguir y separar al libro

1 Situación que no siempre es la más deseable y que no implica una tarea colectiva e integral para representar bibliográficamente a los libros antiguos.

2 Este aspecto lo hemos analizado en el trabajo "Para empezar hay que recordar: formación profesional e investigación del libro antiguo en México”. En Revista Interamericana de Bibliotecología. Vol. 28, núm. 2 (Julio-Diciembre de 2005). p. 157-175. 
incunable, ${ }^{3}$ aunque éste también sea un producto de la imprenta manual, y por otra parte a la edición decimonónica, que se inicia cuando cambia la producción de libros basados en procesos manuales, a mecánicos. ${ }^{4}$ Estas categorías nos permiten separar los conjuntos librarios y, al mismo tiempo, clarificar las peculiaridades materiales del objeto cultural para realizar representaciones bibliográficas y catalográficas de acuerdo con cada estructura.

Así podemos explicar el libro antiguo como el producto de un tiempo específico y como el resultado de un proceso que tiene características culturales, sociales, económicas y políticas definidas. Efectivamente, si comprendemos los modos de fabricación de los libros en un periodo concreto, podríamos acercarnos a los procedimientos de otras épocas que comparten técnicas similares y establecer así puntos de referencia ${ }^{5}$ para el análisis material de los libros.

Es precisamente esta explicación la que contribuye a la comprensión jurídica del libro antiguo como un bien patrimonial, porque a través de la comprensión material del objeto podemos definir sus valores culturales y trasladar esta apreciación hasta una categoría jurídica de protección. Pero ésta se enfrenta a la problemática de las definiciones y los conceptos para identificar bienes culturales, donde la perspectiva de orden epistemológico dentro de una disciplina especializada (como la bibliotecología) debe aportar soluciones, como la que existe respecto al conjunto de los primeros impresos en territorio novohispano, sobre los que todavía se debate entre la denominación de "impresos mexicanos del siglo XVI" o "incunables americanos". 6

En efecto, las leyes mexicanas no definen con precisión aquellos objetos de custodia que se relacionan con bienes bibliográficos. En general los libros antiguos son considerados en la categoría de monumentos históricos, la cual comprende a los impresos mexicanos y extranjeros producidos entre los siglos XVI y XIX. ${ }^{7}$ En esta categoría no se definen características materiales

3 Es el impreso producido desde la invención de la imprenta de tipos móviles hasta 1500. Cfr. Konrad Haebler. Introducción al estudio de los incunables. Madrid: Ollero \& Ramos, 1995. p. $17-18$.

4 Cabe aclarar aquí que también se considera el año de 1550 como cierre del periodo incunable, debido a las diferencias temporales de la introducción de la imprenta en las diferentes ciudades y países. Debido a esta condición, los impresos producidos presentarán características materiales que se acercan a uno $\mathrm{u}$ otro periodo, por lo que pueden ser considerados de forma distinta. Esto se debe a que las técnicas de producción, tanto manuales como mecánicas no se introdujeron al mismo tiempo ni con las mismas peculiaridades en todos los territorios.

5 Roland B. McKerrow. Introducción a la bibliografía material. Madrid: Arco Libros, 1998. p. 46

6 Una reflexión inacabada desde principios del siglo XX y que todavía no se ha resuelto puntualmente. Nuestra postura personal respecto a esta temática ya ha sido explicada. $C f r$. Idalia García. Secretos del estante [Inédito] capítulo $3^{\circ}$.

7 Ley Federal sobre Monumentos y Zonas Arqueológicos, artísticos e históricos. Publicada en el Diario Oficial de la Federación, el 6 de mayo de 1972. Julio César Olivé Negrete y Bolfy Cottom. Leyes estatales en materia del patrimonio cultural. México: INAH, 1997. T. 1, p. 103. A partir de esta consideración se protegen porque "su rareza e importancia para la historia mexicana [justifica que] merezcan ser conservados en el país” 
para identificar conjuntos específicos de protección, y tampoco se establece ninguna consideración sobre las bibliotecas ${ }^{8}$ como las instituciones donde deben resguardarse los libros antiguos. Cuestión ésta que debemos resolver para establecer que la definición de libro antiguo también debe estar estipulada por ley. Es decir, definir como libro antiguo a todo impreso que hay sido "producido desde la invención de la imprenta hasta una fecha que el uso o la ley determinan". ' De esta forma la determinación de la antigüedad se estipularía por ley y, en consecuencia, se establecerían limitaciones para su correcta identificación, valoración, venta y circulación; y también para su uso.

Ahora bien, al elaborar un registro bibliográfico parece existir una confusión entre la descripción catalográfica y la descripción bibliográfica de los libros antiguos. ${ }^{10}$ Esta situación posibilita que las instituciones realicen descripciones diferentes para los mismos libros, lo cual en ocasiones crea confusiones al identificar las ediciones. Pero todo registro debe servir para identificar la existencia de una edición antigua, y para resaltar sus valores textuales e históricos.

Ciertamente las tareas de registro de libros antiguos también involucran recursos materiales, institucionales y humanos. Estos últimos deben orientarse hacia la especialización dada por la dimensión cuantitativa del problema patrimonial que representan. Un problema que está presente en nuestro país desde el siglo XIX, cuando se planteó la necesidad de

considerar cuántas personas se emplearían en registrar no sólo nuestras librerías públicas y particulares; así como los numerosos archivos... donde están reservados los más preciosos documentos de nuestra historia: cuántas manos se necesitarán para recoger todas las páginas que se encuentran esparcidas por todas partes. ${ }^{11}$

La realidad es que las buenas intenciones y los proyectos emprendidos no han logrado consolidar un catálogo colectivo de impresos antiguos en México como una política cultural de largo plazo. Intentar explicar por qué no hemos alcanzado este nivel de registro patrimonial como ha sucedido en otros

8 El aspecto patrimonial de la biblioteca, como entidad de custodia de bienes culturales, es otra condición sobre la que se debe reflexionar para garantizar una verdadera salvaguarda de la riqueza bibliográfica custodiada.

9 José Martínez de Souza. Diccionario de Bibliología y ciencias afines. $2^{\text {a }}$ ed. Madrid: Fundación Germán Sánchez Ruipérez: Pirámide, 1993. p. 540

10 Cfr. G. Thomas Tanselle. "Descriptive Bibliography and Library Cataloguing". En Studies in Bibliography. Vol. 30 (1977). Texto disponible en http://etext.lib.virginia.edu/bsuva/sb/ [Consulta: agosto de 2005].

11 Fortino H. Vera. "Al lector" en José Mariano Beristáin de Souza. Biblioteca hispano Americana setentrional. $2^{a}$ ed. Amecameca: Tipografía del Colegio Católico, 1883. 3 tomos h.3v. (Biblioteca del Instituto Mora). 
países, es un tema que debe ser analizado en otro espacio. Nosotros deberíamos reflexionar sobre el valor cultural que tenemos y el que transmitimos de estos libros y, especialmente, sobre las formas en que los estamos representando bibliográficamente.

\section{FORMAS DE REPRESENTACIÓN BIBLIOGRÁFICA}

La bibliografía es un campo de conocimiento disciplinar cuya noble tradición está relacionada con el registro de impresos antiguos que pueden datarse desde los primeros repertorios elaborados pocos años después de la invención de la imprenta. ${ }^{12}$ Sin embargo para algunos estudiosos sobre este tema, la bibliografía puede documentarse como una práctica que se inicio con la descripción de los libros manuscritos, de ahí que en cierto momento del desarrollo disciplinar, con la introducción de los nuevos soportes de información, se llegase a discutir si la bibliografía tendría competencia frente a estos nuevos objetos.

Por fortuna las respuestas que se han dado a esta interrogante optaron por integrar los nuevos objetos al campo de la bibliografía, más que por disgregar una disciplina que requiere una buena especialización de conocimientos antes de poder representar los diferentes objetos donde la humanidad guarda y transmite su conocimiento e información desde el nacimiento de la cultura escrita. ${ }^{13}$

Aquí lo que nos interesa distinguir es la tradición que se origina con la descripción de los primeros libros producidos a partir del siglo XVI. Una tradición que conformó una práctica de registro bibliográfico que fue evolucionando gradualmente hasta constituir diferentes metodologías propuestas por distintos campos disciplinares y las cuales fueron desarrolladas con finalidades específicas. Pero no será hasta el siglo XVIII cuando se comienza a extender una forma de registro descriptivo que será definido como campo de la bibliografía descriptiva, textual e histórica ${ }^{14}$ y que podemos anotar como antecedentes de la bibliografía material.

La bibliografía material no es definida como tal en las obras que analizan la tipología de los distintos repertorios. ${ }^{15}$ Pese a esto podemos introducir el

12 Luigi Balsano. La bibliografía: historia de una tradición. Gijón: Trea, 1998. p. 26

13 Isabel de Torres Ramírez. "Los estudios de bibliografía en el último cuarto del siglo Xx". En Documentación de las Ciencias de la Información. Vol. 25 (2002). p. 151

14 Robert B. Harmon. Elements of bibliography: a guide to information sources and practical applications. $3^{\mathrm{a}}$ ed. Maryland: The Scarecrow Press, 1998. p. 85-89.

15 Cfr. D. W. Krummel. Bibliografías: sus objetivos y métodos. Madrid: Fundación Germán Sánchez Ruipérez: Pirámide, 1993, e Isabel de Torres Ramírez. ¿Qué es la bibliografía?: introducción para estudiantes de biblioteconomia y documentación. Granada: Universidad, 1996. 
término a través de la traducción realizada en España con los trabajos de McKerrow (1927) y Gaskell (1949), en donde se decidió traducir la aportación metodológica de los anglosajones como "bibliografía material". ${ }^{16}$ Dichas aportaciones constituyen parte del soporte de lo que actualmente podemos denominar bibliografía material ${ }^{17}$ y que ya encontraremos representada en los textos de Proctor, Haebler, Pechellet, Norton y Hendrick, en lo que se refiere a la identificación de incunables sine notis. ${ }^{18}$

Ahora bien, si la cuestión es identificar el tiempo histórico en que apareció la bibliografía material como tal, debemos comprender una sustancial diferencia. Si bien ya se hacía descripción de libros como objetos físicos desde el siglo XVIII, este hacer no era de ninguna manera un concepto, sino más bien una práctica que se retoma a finales del XIX y principios del XX con una nueva perspectiva y finalidad histórica que antes no tenía.

Es ahora cuando podemos hablar de la necesidad práctica de construir un concepto, ya que en el siglo XIX las recién fundadas bibliotecas nacionales debieron enfrentar la identificación y el registro del patrimonio bibliográfico expropiado a la Iglesia y, por tanto, ya no les bastaba con identificar las meras ediciones sino que hacia falta también identificar los objetos portadores de valores.

De la mano de Pollac, McKerrow y Greg (los tres pilares de la aportación anglosajona)

la bibliografía adquirió un nuevo significado y unos nuevos propósitos. En concreto iba a aplicarse no sólo a la catalogación de libros [...] sino también a la elaboración de la información que de esta manera se hace más asequible, completada con el análisis y la interpretación del proceso por el que los manuscritos originales se convirtieron en libros impresos. ${ }^{19}$

La paulatina introducción de estas aportaciones metodológicas se debió a las publicaciones de la Bibliographical Society, fundada en 1892, que se propuso trabajar sobre la identificación de libros antiguos. Se establecieron así los principios y prácticas de los estudios bibliográficos que comprenden al libro antiguo como un objeto físico que posee características materiales particulares. Estas propuestas se han mantenido prácticamente estables hasta nuestros días, gracias a la publicación del trabajo de Bowers en $1949,{ }^{20}$ y a

16 Introducción de José Martínez de Sousa a la obra de Phillip Gaskell. Nueva introducción a la bibliografía material. Gijón. Trea, 1999. p. XIV-XV

17 Manuel Pedraza Gracia, Yolanda Clemente San Román y Fermín de los Reyes Gómez. El libro antiguo. Madrid: Editorial Síntesis, 2004. p. 255

18 Julián Martín Abad. Los libros impresos antiguos. Valladolid: Universidad, 2004. p. 50

19 David McKitterick. "Introducción" de Roland B. McKerrow. Op. cit. p. 16

20 Fredson Bowers. Principios de descripción bibliográfica. Madrid: Arco Libros, 2001. p. 11 
los trabajos que desde la revista Studies in Bibliography ha publicado Thomas Tanselle. $^{21}$

Así, este método bibliográfico toma forma con la síntesis de las tradiciones y busca representar un objeto bibliográfico antiguo de manera individualizada. En esta representación es donde la forma material adquiere relevancia, pues es a través de ésta como el texto de un autor se introduce en el mundo social de los lectores. Esta relación es la más distintiva de la propuesta anglosajona, pero

no es la detallada descripción bibliográfica de las fuentes primarias propuesta por la escuela anglosajona la finalidad de la bibliografía, sino la expresión del resultado del análisis y valoración del material bibliográfico

que se adecuará a los fines en que estas descripciones se utilicen. ${ }^{22}$

La recuperación de los postulados de la bibliografía material en diversos países, ${ }^{23}$ cuando se trata de elaborar repertorios y estudios especializados, así como su propia evolución disciplinar han apuntalado la relevancia de los conceptos de edición, emisión y estado ${ }^{24}$ para comprender cómo un mismo texto presenta variaciones en su producción y, por tanto, cómo esta condición material del libro puede también afectar la transmisión del contenido de las obras.

De ahí que representar estas variantes sea uno de los puntos cruciales de la metodología en cuestión, pues una vez realizada la impresión de una edición no era posible volver a producir más ejemplares de la misma. De ahí que, si fuese necesario, se requeriría de otra composición que daría por resultado otra edición, aun cuando ambas se fecharan el mismo año. Estos conceptos nos remiten a las diferencias existentes en el conjunto de una edición. Diferencias que pueden ser tipográficas e intencionales (emisión) y afectar a la portada, los preliminares o el texto de la obra. Pero que también pueden ser accidentes tipográficos, derivados de una irregularidad presentada en el proceso de composición

21 Los textos de esta publicación se encuentran disponibles en la página http://etext.lib.virginia. edu/bsuva/sb/ [Consultado: julio 2005]

22 Jaime Moll. "La bibliografía en la investigación literaria". En Métodos de estudio de la obra literaria / coordinación de José María Diéz Borque. $1^{a}$ reimp. Madrid: Taurus, 1989. p. 146

23 Cfr. Juan Montero y Pedro Ruíz Pérez. "El libro antiguo en el Siglo de Oro. Estado de la investigación (1980-2005)”. En Etiópicas. Núm 2 (2006). Texto disponible en http://www.uhu. es/programa_calidad_literatura_amatoria/etiopicas/num_2/montero_ruiz.pdf [Consulta: marzo de 2007].

24 Estos conceptos proceden de la tradición anglosajona como parte del análisis propuesto para las distintas variedades que se pueden presentar en los ejemplares de una edición antigua. Phillip Gaskell. Op. cit. p. 391-396; Jaime Moll. Op. cit. p. 169-179; Alberto Montaner Frutos. Prontuario de bibliografía: pautas para la realización de descripciones, citas y repertorios. Gijón: Trea, 1999. p. 133. 
del libro (estado). Lo anterior nos refiere a las formas de producción de los libros antiguos, cuya característica más importante es que el objeto haya sido producido por técnicas manuales.

Pero este conocimiento especializado no queda aislado; por el contrario, comienza a integrarse en las tareas de catalogación de libros antiguos, de forma tal que se manifiestan los requerimientos especiales que tienen estos libros debido a su particular naturaleza y origen. Tanto más si se trata de integrar en la descripción otras características que le añaden valor patrimonial a un libro antiguo, elementos que aunque testimonian la historicidad del objeto bibliográfico, no han estado siempre presentes en los repertorios bibliográficos.

Es por eso que el reconocimiento actual del libro antiguo como un objeto conformado por valores textuales, ${ }^{25}$ y por valores históricos, ${ }^{26}$ que soportan y justifican su comprensión patrimonial. Este conjunto de atributos es pues lo que nos permite entender y conocer tal objeto como un producto de su tiempo, y en relación con sus semejantes. Pero al mismo tiempo nos permite valorar la historia de ese libro como un producto social que ha sido poseído y utilizado. $^{27}$

Solamente considerando la inclusión de este tipo de información en la representación bibliográfica, es que se pueden contrastar todas las ediciones conservadas ${ }^{28}$ de un impreso antiguo y así, determinar las diferencias sustanciales entre ellas. Pero esta maniobra requiere la aplicación de conocimientos específicos, que puedan transmitir los valores citados y el potencial informativo que se les reconoce como objetos bibliográficos. Consideraciones y conocimientos que han estado presentes en el desarrollo de las reglas de catalogación y los principios de descripción bibliográfica durante todo el siglo XX, y cuya elaboración aún prosigue.

\section{LA DESCRIPCIÓN BIBLIOGRÁFICA MATERIAL DE UN LIBRO ANTIGUO: RECUPERACIÓN DE LA TRADICIÓN}

Para analizar cómo se ha introducido esta propuesta metodológica en nuestro entorno debemos primero identificar lo que constituye nuestra propia tradición

25 Aquellos que testimonian el proceso de la impresión tipográfica, y que caracterizan o distinguen a un taller de impresión.

26 Aquellos que testimonian el devenir en el tiempo de un objeto. Lorenzo Baldacchini. Il libro antico. Urbino: La Nuova Italia Científica, 1982. p. 13-14

27 Debemos diferenciar ambos procesos, ya que el primero se relaciona más con la bibliofilia y el segundo más con el mundo de la lectura. Ambos son relevantes para la historia del libro porque nos permiten comprender al objeto desde su producción hasta su posterior introducción en la vida social y los avatares que ésta haya tenido hasta su custodia contemporánea.

$22 \quad 28$ Lo que Julián Martín Abad comprende como identificación editorial (2004). Op. cit. p. 61 
bibliográfica. Hoy nadie discute la relevancia que tiene la Bibliotheca Mexicana de Juan José de Eguiara y Eguren como el primer repertorio producido en territorio mexicano, aunque este impresionante trabajo se enfocó más a la descripción de los autores que a la de los propios libros. Sin embargo Eguiara sentó las bases de una tradición bibliográfica que se enriqueció con los trabajos posteriores de José Mariano Beristáin de Souza, ${ }^{29}$ Joaquín García Icazbalceta, ${ }^{30}$ Vicente de Paula Andrade, ${ }^{31}$ Nicolás León, ${ }^{32}$ y el chileno José Toribio Medina. ${ }^{33}$

Todos estos repertorios, exceptuando el de Eguiara, se realizaron mientras se consolidaba la propuesta anglosajona en materia de bibliografía, durante el siglo XIX, al paralelo con el fortalecimiento de la bibliofilia y el mercado del libro. Pero también durante ese periodo una parte importante de la herencia bibliográfica mexicana se perdió por destrucción, o pasó a formar parte de otras colecciones internacionales. De lo que no cabe duda es de que esos repertorios constituyen la parte más trascendente de nuestra tradición y el soporte medular de cualquier trabajo histórico contemporáneo interesado en la cultura bibliográfica del pasado mexicano.

La continuidad de la tradición bibliográfica mexicana fue de la mano de los trabajos de Valton, ${ }^{34}$ Wagner ${ }^{35}$ y Fernández de Cossio, ${ }^{36}$ quienes solamente se dedicaron a enriquecer la información sobre los impresos mexicanos del siglo XVI. Posteriormente ese conocimiento y forma de representación de los impresos antiguos, se fue apartando del conocimiento especializado y gradualmente olvidando, hasta aparentemente desaparecer en México. Eso es lo que muestra la práctica bibliográfica que se desarrolló en nuestro país durante la segunda mitad del siglo XX y que perdura actualmente. ${ }^{37}$

El último eslabón del conocimiento bibliográfico que nos preocupa y que motiva esta reflexión es la escasa investigación histórica y cultural que se

29 José Mariano Beristáin de Souza. Op. cit.

30 Joaquín García Icazbalceta. Bibliografía mexicana del siglo XVI: catálogo razonado de libros impresos en México. México: Librería de Andrade y Morales, Sucesores, 1886.

31 Vicente de Paula Andrade. Ensayo bibliográfico mexicano del siglo XVII. $2^{a}$ ed. México: Imprenta del Museo Nacional, 1899.

32 Nicolás León. Bibliografía mexicana del siglo XVIII. México: Imprenta de la Viuda de Francisco Díaz de León, 1902-1908.

33 José Toribio Medina. La imprenta en México, 1539-1821. Santiago de Chile: Impreso en Casa del Autor, 1912. 8 tomos.

34 Emilio Valton. Impresos mexicanos del siglo XVI (incunables americanos) en la Biblioteca Nacional de México, el Museo Nacional y el Archivo General de la Nación. México: UNAM, 1935

35 Enrique W. Wagner. Nueva bibliografía mexicana del siglo XVI: suplemento a las bibliografías de Don Joaquin García Icazbalceta, Don José Toribio Medina y Don Nicolás León. México: Editorial Polis, 1940

36 Francisco González de Cossio. La imprenta en México, 1153-1820: 510 adiciones a la obra de José Toribio Medina en homenaje al primer centenario de su nacimiento. México: Universidad Nacional de México, 1952

37 Cfr. Idalia García. Op. cit. Capítulo $4^{\circ}$. 
realiza en México y que debería basarse en esa fuente de conocimiento que representan los libros antiguos. En efecto, a pesar de la enorme cantidad de libros antiguos que conservamos, todavía son muchas las parcelas del conocimiento relacionadas con la historia del libro y de las bibliotecas en México que prácticamente se desconocen.

En nuestra opinión esta exigua atención a un tema tan rico y esencial para el conocimiento de la cultura del país, se relaciona en gran parte con el problema del registro y la identificación del conjunto de libros antiguos conservados en instituciones nacionales. Indudablemente que esta información, sumada a otros esfuerzos, aportaría datos fiables para el desarrollo de la investigación histórica de esos libros y sus relaciones con el pasado.

Cabe decir que la identificación y registro de un libro antiguo es solamente el principio de una investigación especializada, pero también el de un conocimiento sobre el legado bibliográfico conservado. Porque todo registro constituye también una forma de valoración, en tanto que

el valor bibliográfico, esto es, cultural, [...] importa al desarrollo integral de México. Con él se va a fortalecer nuestra conciencia cultural, base primordial para reafirmar nuestra identidad. [Pero ello implica] comprender que es indispensable elaborar nuestro inventario cultural y que ese inventario no sólo debe ser repletar volúmenes y discos con simples registros que, sin comprensión, no son sino una masa amorfa que se puede cuantificar, pero no analizar razonable ni inteligentemente. $^{38}$

Precisamente una de las tareas de la descripción bibliográfica es saber con certeza cuáles y cuántos son los libros antiguos y, especialmente, si todos los ejemplares existentes de una obra en particular pertenecen a la misma edición o existen variantes de ésta. Esta es una posibilidad fáctica que permite la descripción bibliográfica material ya que incluye entre otros datos, el registro a los autores, el título de las obras, los años de impresión e impresores, su formato y tamaño, una breve descripción de los preliminares, grabados, colofón, y repertorios en donde se ha registrado anteriormente; opiniones sobre la obra que se describe, si existen reimpresiones y en algunos casos la transcripción de una parte del texto que el bibliógrafo ha considerado importante. ${ }^{39}$

38 Ernesto de la Torre Villar. "El trabajo bibliográfico en México". En Nueva Gaceta Bibliográfica. Nos. $23 / 24$ (julio-diciembre 2003). p. 16

39 Esta parte del registro constituye actualmente una fuente de información histórica original invaluable. 
Toda esta información puede ser incluida en la catalogación moderna de acuerdo con normas internacionales como la ISBD (A). ${ }^{40}$ Aunque generalmente no es así, porque se tiende más a la elaboración de descripciones breves que no representan los atributos que la investigación especializada requiere. ${ }^{41}$ En parte esta práctica también contribuye a que la descripción bibliográfica material sea considerada en nuestro país de escaso valor académico, y se piense poco relacionada con las tareas de la investigación histórica y cultural. Apreciación que olvida que ese tipo de descripción se basa en un profundo conocimiento del objeto bibliográfico desde sus formas de producción hasta las de su socialización.

Una búsqueda de impresos antiguos en los catálogos de diferentes bibliotecas del mundo, ${ }^{42}$ nos mostrará diferentes formas de representación en donde se privilegian unos datos frente a otros, según la valoración que se tenga de los libros antiguos. Sin embargo se ha extendido cada vez más, como lo ha promovido la bibliografía material, la inserción de datos relevantes para la identificación, como lo pueden ser signaturas, formato, ilustraciones relevantes, preliminares distintivos, referencias bibliográficas o elementos históricos característicos del ejemplar. Justamente, las formas de registro, en tanto representación y valoración del libro antiguo, permiten analizar diferencias y semejanzas en la representación de un mismo objeto.

Para ejemplificar lo anterior integramos (ver anexo uno), dos registros que nos permiten analizar en que forma la representación bibliográfica de un libro antiguo tiene que ver con un proceso adecuado de identificación de la fuente original. Si comparamos ambos registros, observaremos que se trata de la misma obra, como lo indica la transcripción cuasi facsimilar de la portada y el colofón. Empero el registro elaborado en México parece haber construido una edición imaginaria, ${ }^{43}$ lo que demuestra una particularidad relacionada con el valor y la representación del objeto, así como con el conocimiento metodológico de la bibliografía material.

Por estas razones, sostenemos y compartimos que la representación bibliográfica debe ser

$40 \operatorname{ISBD}(A)$ : descripción bibliográfica internacional normalizada para publicaciones monográficas antiguas / tr. al español, realizada por Ana Baltar Gómez, Fabiola Labella Rivas, Luis Villén Rueda. $2^{a}$ ed. Rev. Madrid : Asociación Española de Archiveros, Bibliotecarios, Museólogos y Documentalistas, Arco Libros, 1995.

41 Kate Simpson Moriarty. Descriptive Cataloging of Rare Materials (Books) and its predecessors: A History of Rare Book. Cataloging Practice in the United States. North Carolina: The Author, 2004. (Master of Science in Library Sciences. University of North Carolina) p. 8

42 Algunos impresos pueden recuperarse a través de la Online Computer Library Center (http:// www.oclc.org/) o más específicamente en el catálogo Internacional KVK (http://www.ubka. uni-karlsruhe.de/kvk/kvk/kvk_span.html)

43 Julián Martín Abad. La imprenta en Alcalá de Henares, 1502-1600. Madrid: Arco Libros, 1991. T. 1, p. 285-290. 
[...] el resultado del análisis material del libro antiguo [...y] expresarse mediante una descripción que dé cuenta de las particularidades de la conformación física de la edición y de sus variantes. ${ }^{44}$

Esta tarea puede realizarse aplicando la metodología de la bibliografía material para distinguir los valores textuales e identificar una obra antigua sin equívocos; una labor imprescindible si se pretende resaltar el valor histórico y contribuir así al conocimiento patrimonial de la producción bibliográfica del pasado.

Por otra parte, las aportaciones de la catalogación para este tipo de libros recomiendan el uso de la norma internacional ya citada, con el ánimo de favorecer las tareas de cooperación e intercambio entre las bibliotecas. Tal normativa recomienda el espacio de las notas para introducir aquellos elementos que forman parte del valor textual y que pueden considerarse como trascendentes para la identificación: signaturas, tipo de portada o grabados distintivos, pero que igualmente se utilizan para registrar aquellos elementos que constituyen el valor histórico que diferencia a unas obras de otras.

Sin embargo, en esta tesitura sería más pertinente emplear la metodología catalográfica descriptiva propuesta por la Library of Congress en su Descriptive Cataloging of Rare Books (DCRB), ${ }^{45}$ que propone un registro más detallado de los ejemplares. Esta propuesta ya se aplica para catalogar libros antiguos en numerosas instituciones, particularmente las norteamericanas, ${ }^{46}$ y se justifica porque se entiende que se conservan pocas copias de muchos de los libros antiguos, y por tanto el espacio del catálogo sería reducido para su representación.

En efecto el registro de datos textuales e históricos es más complejo para una mera representación catalográfica de la obra registrada. Pero este tipo de representación puede tener un punto medio como el que ya se realiza en el Catálogo Nautilo de la Biblioteca Nacional de México, ${ }^{47}$ aunque en éste no siempre se registren las signaturas o, también en el Catálogo Colectivo del $\mathrm{Pa}$ trimonio Bibliográfico Español, ${ }^{48}$ en el que se registran los valores textuales

44 Mercedes Fernández Valladares. "Análisis material y control bibliográfico del libro antiguo: un ejemplo a propósito de la obra de Martín de Frías”. Revista General de Información y Documentación. Vol. 8, no. 1 (1998) p. 30

45 Información disponible de la segunda edición de 1991, en la página http://www.itsmarc.com/ crs/rare0170.htm [Consulta: marzo de 2007]. Esta propuesta está en revisión desde el 2004 y pasa a denominarse Descriptive Cataloging of Rare Materials (Books), en sus siglas DCRM(B).

46 Puede consultarse el libro Association of College and Research Libraries. Examples to Accompany Descriptive Cataloging of Rare Books. 2nd edition. Chicago: American Library Association, 1999.

47 Se puede consultar en la página http://132.248.77.3:8991/F [Consulta: agosto de 2005]

48 Puede consultarse lo correspondiente a esta obra (número de control CCPB000185031-8) en la página http://www.mcu.es/ccpb/ [Consulta: agosto de 2005] 
más relevantes y también los históricos, relacionándolos siempre de forma breve con los ejemplares custodiados con objeto de "caracterizar al ejemplar". 49

De esta manera se estaría posibilitando un diálogo razonable entre la bibliografía material y la catalogación descriptiva, para que la identificación del legado bibliográfico conservado sirva también en la inevitable tarea del control patrimonial. Sin embargo, si observamos (anexo 2) esta aplicación descriptiva veremos cuán complicado resulta integrar esos valores en un registro catalográfico.

\section{A MODO DE CONCLUSIÓN: UNA PROPUESTA DE REPRESENTACIÓN BIBLIOGRÁFICA}

La identificación de una obra antigua es solamente el primer paso de la investigación especializada, pero también del control patrimonial de las colecciones de libros antiguos. Como hemos podido constatar ${ }^{50}$ la descripción detallada suele emplearse para elaborar repertorios específicos (como las bibliografías históricas) o para hacer catálogos de exposiciones bibliográficas. Pero en la representación de este tipo de repertorios que se han realizado en México hemos observado una diversidad interesante en los registros porque se mezcla metodologías bibliográficas de muy distinta procedencia y que fueron propuestas para representar diferentes objetos.

Un conocimiento más detallado de estos libros más allá de su mera identificación, necesariamente involucra conocimientos particulares como los relacionados con la historia del libro o la imprenta, y sin ellos se dificulta la representación de un libro antiguo, la cual es especialmente relevante en relación con ese mismo conjunto patrimonial.

Con esta intención patrimonialista, proponemos un modelo de registro que pretende representar equitativamente los valores textuales e históricos de esos libros (un ejemplo completo puede verse en el anexo 3). Nuestra aplicación metodológica recupera aquellos elementos ya considerados en la tradición bibliográfica que nos antecede, y las propuestas modernas en esta materia desarrolladas en los últimos años por diversas escuelas.

El modelo pretende servir para la elaboración de un repertorio bibliográfico que se sume a los esfuerzos de la catalogación colectiva. Así, siguiendo

49 María Marsá. La imprenta en los Siglos de Oro. Madrid: Ediciones del Laberinto, 2001. p. 72 73

50 Lo hemos realizado al realizar la investigación titulada "Los bienes bibliográficos y documentales de México: valor cultural, función social y garantía de acceso a la información”. 
las recomendaciones de registro indicadas ya por Moll, ${ }^{51}$ la aplicación metodológica que proponemos ${ }^{52}$ se integra con los siguientes elementos:

1) Descripción breve (autor, titulo abreviado y pie de imprenta);

2) Transcripción cuasi facsimilar de la portada;

3) Formato, tamaño, signaturas y descripción física;

4) Relación del contenido de la obra (preliminares, texto de la obra, índice, tabla y colofón);

5) Notas en el siguiente orden: marcas de fuego, ex libris y sellos, anotaciones manuscritas, elementos de ilustración relevantes, encuadernación, estado de conservación; y otras tales como errores tipográficos, en signaturas, foliatura o paginación o faltantes relevantes, y número de líneas en la caja de texto;

6) Biblioteca de custodia y forma de ordenamiento y

7) Repertorios bibliográficos en que haya sido registrada la obra.

Ahora bien, para explicar de forma sintética estos elementos debemos indicar que para la descripción breve en el registro del autor es conveniente identificar la orden religiosa de procedencia, si es el caso. ${ }^{53}$ En cuanto a la transcripción cuasi facsimilar de la portada, deben respetarse la lengua y la ortografía de la época, no deshacerse las abreviaturas, respetar las mayúsculas y minúsculas y las características de la tipografía en cuanto al color y el tipo, ${ }^{54}$ así como todos los tipos presentes (incluidos los decorativos), y debe intentarse emular la tipografía empleada en el original. ${ }^{55}$

Tampoco debe olvidarse en esta transcripción indicar los grabados de portada, las marcas de impresor ${ }^{56}$ y otros elementos tipográficos que deben

51 Jaime Moll. Op. cit. p. 177-178.

52 La propuesta de esta descripción se encuentra más detallada en Idalia García. Op. cit. capítulo $6^{\circ}$.

53 Las más comunes se abrevian de la siguiente manera: Agustinos (O.S.A.), Carmelitas (O.C.) Carmelitas descalzos (O.C.D.), Dominicos (O.P.), Franciscanos (O.F.M.), Jesuitas (S.I.) y Mercedarios (O. de M.). Estas y otras órdenes las recuperamos del apéndice VI de las Reglas de catalogación: edición nuevamente revisada. Madrid: Ministerio de Educación, Cultura y Deporte. Dirección General del Libro, Archivos y Bibliotecas: Boletín Oficial del Estado, 2003. p.543-545.

54 Esta transcripción puede hacerse indicando entre corchetes el color [roj.] [neg.] y el tipo [curs.] [red.] cuando se transcribe de forma manuscrita, ya que trabajando directamente en un archivo electrónico se puede utilizar directamente los tipos y colores empleados por el impresor antiguo siempre que sea posible.

55 Existen diversas fuentes de computadora (tipografía digital) que pueden ser empleadas para esto, especialmente en lo que corresponde a la "s" larga o las letras ligadas (como ae, ct, st) que corresponden a un sólo tipo de imprenta. Cfr. José Martínez de Sousa. Diccionario de edición, tipografía y artes gráficas. Gijón: Trea, 2001. p. 273

56 Conviene recordar que solamente se debe indicar una marca de impresor cuando se ha verificado esta información en los repertorios existentes, ya que los grabados de portada pueden confundirse con éstas. Un instrumento útil para esta identificación correcta puede ser el desarrollado en la Universidad de Barcelona y disponible en la página http://eclipsi.bib.ub.es/ imp/impcat.htm [Consulta: agosto 2005] 
indicarse entre corchetes. Una descripción así de detallada permite tener una idea más precisa sobre la portada que se describe, ${ }^{57}$ y facilita la comparación entre los diferentes ejemplares conservados. Presentamos aquí un ejemplo de lo que sugerimos: ${ }^{58}$

\section{CARTILLA / Y DOCTRINA / ESPIRUTVAL / PARA / LA CRIANZA, Y} EDVCACION / de los Nouicios que tomaren el Habito / en la Orden de nueftro Padre / San Francifco. / EN LA QVAL BREVEMENTE, / Je les enfeña lo que deuen hazer, conforme / à la Doctrina de nueftro Seraphico Doctor San Buenaventura, y à lo que $\int \mathrm{e}$ v $\mathrm{a}$, y / practica en efta Santa Prouincia de Santiago. / REVISTA, Y MANDADA IMPRIMIR / por el Padre Fray Luis de miranda, Miniftro / Prouincial de la dicha Prouincia, por / la gran falta que avia della. / [filete] / Con licencia del Ordinario. / En Salamanca, por Sufaña Muñoz Viuda: Año de M.DC.LII. ${ }^{59}$

Posteriormente registramos el formato, el tamaño, las signaturas, y la descripción física de un material (número de páginas), para representar la estructura material de un libro antiguo, lo que nos refiere al proceso de cómo se hacían esos libros. El más complejo de estos datos es el de las signaturas empleadas para numerar los cuadernillos ${ }^{60}$ utilizados en la impresión, porque requiere de la revisión completa del ejemplar que se describe.

El orden que proponemos aquí es el formato, el tamaño (en milímetros), el orden de las signaturas, y las hojas y páginas que componen la obra. ${ }^{61}$ Si bien existen diversas maneras de representar la estructura ${ }^{62}$ de un libro antiguo, debemos precisar que ahí donde la hoja no esté numerada (con signatura,

57 Ciertamente en esta descripción no indicamos el tamaño de los tipos presentes en la portada, ni tampoco los tamaños que corresponden a los tipos del texto. Algunos autores sí consideran relevante el registro de esta información, pero debe indicarse en las notas cuando el método mismo lo requiere o la minuciosidad del registro así lo exige. $C f r$. Fredson Bowers. Op. cit. p. 191-192 y Alberto Montaner Frutos. Op. cit. p. 148-155.

58 Para esta propuesta se ha utilizado la tipografía digital DICE desarrollada en la Universidad de Zaragoza (España).

59 Biblioteca Ernesto de la Torre Villar del Instituto Mora, R 255.3 CARy.

60 Cada pliego doblado compone un cuadernillo y determina el formato de éste. El proceso legal de impresión imperante en la época, determinó que se imprimiera primero el texto y después los preliminares (documentos legales que anteceden al texto de una obra necesarios para realizar una impresión, y algunos otros como las dedicatorias o poesías), de ahí que en el texto se emplearan signaturas alfabéticas para el texto y, en los preliminares signaturas simbólicas (J, $\S, \dagger, *$, entre otros). Ciertamente se han desarrollado métodos para deducir la forma de las signaturas, sin embargo sólo la revisión puntual del objeto nos permitirá identificar los errores o variaciones que éstas presentan.

61 La estructura básica de un libro antiguo por norma general es la siguiente: hojas, páginas, hojas o también hojas, folios, hojas. Cuando no existe ningún tipo de numeración siempre son hojas y así se describen.

62 Alberto Montaner Frutos. Op. cit. p. 138-141. 
paginación o foliación) lo más correcto es indicar su existencia entre corchetes para evitar confusiones. De esta manera la forma de transcripción sería la siguiente:

$$
8^{\text {o }} ;(170 \mathrm{~mm}) ;[1] \star^{8}, \star \star^{4}, \mathrm{~A}-\mathrm{Z}^{8}, \mathrm{Aa}-\mathrm{Bb}^{8}, \mathrm{Cc}^{4} ;[13], 395 \text { p. [6]. }{ }^{63}
$$

En cuanto a la descripción del contenido, podemos decir tres cosas fundamentales. La primera se refiere a la pertinencia de indicar el tipo de portada que existe en el libro que describimos. ${ }^{64}$ La segunda, es que una hoja es bidimensional y que ambas caras se denominan recto y verso (frente y reverso); por tanto la transcripción de cada parte del libro debe indicar el recto o verso donde inicia o, por el contrario, el verso o recto de la misma manera se indica en dónde termina. ${ }^{65}$

La tercera, y que afecta específicamente al registro de los preliminares, es que en éstos debe identificarse el tipo de preliminar ${ }^{66}$ del que se trata, la persona responsable de ese documento incluyendo la orden religiosa de pertenencia (si la hubiere), el cargo o actividad más relevante que nos permita relacionarlo históricamente, y también el lugar y la fecha del documento. De esta manera, es posible conocer qué tipo de preliminares existen en un libro antiguo y los personajes históricos que participaron en el proceso de impresión, control y censura del libro en cuestión. Toda esta información se transcribiría de la siguiente manera:

h.2.r.: Licencia de Impresión. Pedro de Zamora Hurtado. Toledo, 17 de Septiembre de $1646 .^{67}$

La última parte del modelo, el espacio dedicado a las notas, suele ser la más abundante en datos. Solamente establecemos aquí las consideraciones generales que nos parecen pertinentes. La marca de fuego, el ex libris y el sello, identifican la precedencia institucional o personal del libro que se describe,

63 Corresponde a la obra Joseph Vidal. Memorias tiernas, despertador afectuoso y devociones practicas con los dolores de la Santissima Virgen... En Amberes: por Henrico y Cornelio Verdussen, 1695 (Biblioteca Eusebio Francisco Kino 024010)

64 Entre éstas se encuentran la portada orlada, con orla tipográfica, a doble tinta, con frontispicio, grabada y enmarcada.

65 También es pertinente indicar dónde existen hojas en blanco.

66 Se pueden identificar claramente los tipos de preliminares que se utilizaron, consultando la obra de José Simón Díaz. El libro español antiguo. Madrid: Ollero \& Ramos, 2000.

67 Regla de la gloriosa Santa Clara con las constituciones de las monjas capuchinas... Reimpressa en Mexico: en la Imprenta del Lic. Don Joseph de Jauregui, [1646] Fecha de edición tomada de la licencia. h.2r. (Biblioteca Eusebio Francisco Kino 023878) 
pero también nos ayudan a conocer cómo se ha movido ese objeto en el tiempo. ${ }^{68}$

La anotación manuscrita es la parte más interesante del objeto leído y poseído; su naturaleza nos permite identificar cuando menos cuatro tipos distintos: propiedad, lectura, censura y expurgo. Debido a su importancia y característica como elemento histórico, no creemos conveniente describir la anotación manuscrita de propiedad como "ex libris manuscrito", ya que crea una confusión con el propio ex libris y su naturaleza histórica. ${ }^{69}$

En cuanto a los elementos de ilustración consideramos pertinente registrar los más visibles socialmente, siempre que sean relevantes. Dada su naturaleza gráfica, debemos indicar el tamaño en milímetros (largo por ancho), ya que la experiencia nos ha mostrado que son éstos elementos los más sensibles al saqueo selectivo, pero también porque son importantes para la historia de la impresión antigua.

La descripción de la encuadernación, ${ }^{70}$ suele reducirse a dos tipos: "de pergamino" o "de época”, términos que no aportan mucha información. En este sentido, creemos que para caracterizar un tipo de encuadernación debemos cuando menos registrar el material del que está hecha (pergamino, piel, papel, etcétera) y el tipo de decoración que presenta el lomo, las tapas y los cantos. ${ }^{71}$ Relacionado directamente con la encuadernación existe el volumen facticio, aquel que se ha elaborado para conservar conjuntamente varias obras y que suele identificarse con la miscelánea. ${ }^{72}$ Aquí importa distinguir cuándo se registran obras contenidas en este tipo de volúmenes, para lo que resulta conveniente señalar "encuadernado con" cuando el registro bibliográfico se realiza sobre el primero existente, y "encuadernado en" cuando se registran los subsecuentes del mismo volumen.

También creemos pertinente informar sobre el estado de la conservación del libro que se describe por dos consideraciones puntuales. La primera es

68 Actualmente en nuestro país contamos con escasos instrumentos para su correcta identificación, por ello, la inclusión en el registro (tanto catalográfico como bibliográfico) nos acercaría a su conocimiento y a consolidar un panorama general que sirviera de base para hacer estudios históricos en esta materia.

69 Juan Delgado Casado. Los ex libris españoles. Valencia: Vincet García Editores, 1996. p. 6-7

70 Otro elemento histórico sobre el que existe escasa valoración en los fondos antiguos mexicanos. Cuestión que ha favorecido la sustitución y destrucción indiscriminada de las encuadernaciones originales.

71 Especialmente cuando se trata de una decoración distintiva, por ejemplo los cantos salpicados en rojo. Para este tipo de características se recomienda leer a Lucía Torner Morales. "El estudio material del libro antiguo: El análisis de guardas, cantos y planos decorados”. En XVIII Encuentro de Investigadores. Del pensamiento novohispano. Noviembre de 2005.

72 Denominación que es más propia del material de archivo, ya que en este tipo de volúmenes se integran tanto impresos de distintas épocas como manuscritos. Este tipo de volumen es más contemporáneo que el facticio, y normalmente fue realizado en instituciones contemporáneas. Por su parte el facticio suele contener impresos relacionados por tema, época, autor o incluso impresor y parecen proceder de la intención de un bibliófilo. 
que esos datos ayudan a caracterizar un libro concreto, ya que no todos los libros envejecen y se deterioran de la misma forma. ${ }^{73}$ La segunda, es que esa misma información podría servir en el futuro para analizar factores de deterioro y definir políticas de conservación a largo plazo.

Finalmente asentar en las otras notas errores relevantes en signaturas, paginación, foliación o meramente tipográficas, así como el tamaño de la caja de texto nos ayuda a definir emisiones y estados. La intención de este conjunto de notas es principalmente distinguir los valores históricos del libro antiguo que nos permite acercarnos a la comprensión de su procedencia. De esta manera comprenderíamos mejor su uso a lo largo del tiempo, desde que fue impreso hasta su custodia actual. Así también podríamos ubicar colecciones del pasado, a pesar de que estén distribuidas en diferentes instituciones contemporáneas.

Para terminar esta propuesta de registro consideramos conveniente que se aporte la referencia de los repertorios bibliográficos en que haya sido registrada la obra, de la manera siguiente: "Palau y Dulcet (segunda edición), 1, p. 117" ${ }^{74}$ También recomendamos se indique la biblioteca en donde se encuentra el ejemplar descrito, conjuntamente con las formas de ordenamiento que se corresponden. En último lugar, si se han identificado otros ejemplares de la edición que se describe es conveniente anotarlos.

Sin duda la investigación especializada en libros antiguos implica responsabilidad en las tareas de salvaguarda de un conjunto de bienes que han sido considerados patrimoniales. El registro puntual y preciso de la fuente empleada en la investigación ayudará a que otros recuperen la misma fuente y puedan hacer su propio trabajo de interpretación.

La realidad es que no podemos garantizar con plena certeza la salvaguarda de estos libros debido a nuestra problemática legal y a la apreciación sobre el trabajo bibliográfico. Pero la conjunción de la tradición bibliográfica con las aportaciones metodológicas de la bibliografía material puede ser empleada para distinguir la condición patrimonial de un libro antiguo y así documentar sin equívocos la tutela de un bien cultural.

73 Lamentablemente los restauradores y conservadores no siempre consideran la necesidad de documentar su proceso y hemos comprobado que esta información puede llegar a ser sumamente útil en la identificación patrimonial de un libro antiguo. En este sentido indicar cómo estado de conservación bueno, regular o malo, no aporta mucho ya que es una apreciación totalmente subjetiva. Se podría corregir esta tendencia indicando si existe ataque de xilófagos, si el lomo está desprendido o si las hojas están oxidadas para agregar mayores datos a esa descripción subjetiva.

74 Siguiendo las recomendaciones del libro Standard citation forms for published bibliographies and catalogs used in rare books cataloguing / prepared by Peter M. Van Wingen and Belinda D. Urquiza. 2nd ed. Washington: Library of Congress, 1996. p. xxvi y 94. 


\section{BibLIOGRAFÍA DE REFERENCIA}

Abad, Julián Martín. La imprenta en Alcalá de Henares, 1502-1600. Madrid: Arco Libros, 1991. $2 \mathrm{t}$ 2004. Los libros impresos antiguos. Valladolid: Universidad,

"La tipobibliografía complutense del siglo XVI: tareas y posibilidades". En El Libro Antiguo Español: Actas del primer coloquio internacional / al cuidado de María Luisa López Vidriero y Pedro M. Cátedra. $1^{a}$ reimp. Salamanca: Universidad: Biblioteca Nacional de Madrid: Sociedad Española de Historia del Libro, 1993. p. 273- 293.

Association of College and Research Libraries. Examples to Accompany Descriptive Cataloging of Rare Books. 2nd edition. Chicago: American Library Association, 1999.

Baldacchini, Lorenzo. Il libro antico. Urbino: La Nuova Italia Científica, 1982.

Balsano, Luigi. La bibliografía: bistoria de una tradición. Gijón: Trea, 1998.

Beristáin de Souza, José Mariano. Biblioteca bispano Americana setentrional. $2^{a}$ ed. Amecameca: Tipografía del Colegio Católico, 1883. 3 tomos.

Bowers, Fredson. Principios de descripción bibliográfica. Madrid: Arco Libros,

Carreño Velásquez, Elvia. Fondo Conventual de la Biblioteca Nacional de Antropología e Historia: Catálogo de la Biblioteca del Convento Grande de San Francisco de la Ciudad de México, V. México: INAH, 2000.

Clemente San Roman, Yolanda. "Las tipobibliografías como repertorios útiles para la investigación”. En Cuadernos de Documentación Multimedia. No. 10 (2000) Texto disponible en http://www.ucm. es/info/multidoc/multidoc/revista/num10/paginas/pdfs/yclemente.pdf [Consulta: Junio de 2005]

Delgado Casado, Juan. Los ex libris españoles. Valencia: Vincet García Editores, 1996.

Fernádez Valladares, Mercedes. "Análisis material y control bibliográfico del libro antiguo: un ejemplo a propósito de la obra de Martín de Frías". En Revista General de Información y Documentación. Vol. 8, no. 1 (1998). p. 11-37

García, Idalia. "Para empezar hay que recordar: formación profesional e investigación del libro antiguo en México. En Revista Interamericana de Bibliotecología. Vol. 28, núm. 2 (Julio-Diciembre de 2005). p. 157-175.

Secretos del estante. [Inédito 2007].

García Icazbalceta, Joaquín. Bibliografía mexicana del siglo XVI: catálogo razonado de libros impresos en México. México: Librería de Andrade y Morales, Sucesores, 1886. (Edición del FCE, 1954) 
Gaskell, Phillip. Nueva introducción a la bibliografía material. Gijón: Trea, 1999.

González de Cossio, Francisco. La imprenta en México, 1153-1820: 510 adiciones a la obra de José Toribio Medina en homenaje al primer centenario de su nacimiento. México: Universidad Nacional de México, 1952.

Harmon, Robert B. Elements of bibliography: a guide to information sources and practical applications. 3erd edition. Maryland: The Scarecrow Press, 1998.

Herrero Pascual, Cristina. "Metodología para un catálogo de libros del siglo XVI". En Revista General de Información y Documentación. Vol. 6, no. 2 (1996). p. 10-50.

Huarte Morton, Fernando. "La descripción de los libros raros". Primeras Jornadas de Bibliografia. Madrid: Fundación Universitaria Española, 1977. p. 65-69.

Krummel, D.W. Bibliografías: sus objetivos y métodos. Madrid: Fundación Germán Sánchez Ruipérez: Pirámide, 1993.

$\operatorname{ISBD}(A)$ : descripción bibliográfica internacional normalizada para publicaciones monográficas antiguas / tr. al español, realizada por Ana Baltar Gómez, Fabiola Labella Rivas, Luis Villén Rueda. 2ª ed. Rev. Madrid : Asociación Española de Archiveros, Bibliotecarios, Museólogos y Documentalistas, Arco Libros, 1995.

León, Nicolás. Bibliografía mexicana del siglo XVIII. México: Imprenta de la Viuda de Francisco Díaz de León, 1902-1908.

Marsá, María. La imprenta en los Siglos de Oro. Madrid: Ediciones del Laberinto, 2001.

Martínez de Souza, José. Diccionario de bibliología y ciencias afines. 3era ed. Gijón: Trea, 2004. Trea, 2001. Diccionario de edición, tipografía y artes gráficas. Gijón:

Mckerrow, Roland B. Introducción a la bibliografía material. Madrid: Arco Libros, 1998.

Medina, José Toribio. La imprenta en México, 1539-1821. Santiago de Chile: Impreso en Casa del Autor, 1912. 8 tomos.

Moll, Jaime. "La bibliografía en la investigación literaria". En Métodos de estudio de la obra literaria / coordinación de José María Diéz Borque. $1^{a}$ reimp. Madrid: Taurus, 1989. p. 145-182.

Montaner Frutos, Alberto. Prontuario de bibliografía: pautas para la realización de descripciones, citas y repertorios. Gijón: Trea, 1999.

Montero, Juan y Pedro Ruíz Pérez. "El libro antiguo en el Siglo de Oro. Estado de la investigación (1980-2005)”. En Etiópicas. Núm. 2 (2006). Texto disponible en http://www.uhu.es/programa_calidad_literatura_amatoria/etiopicas/num_2/montero_ruiz.pdf [Consulta: marzo de 2007].

Olivé Negrete, Julio César y Bolfy Cottom. Leyes estatales en materia del patrimonio cultural. México: INAH, 1997. 3 tomos. 
Paula Andrade, Vicente de. Ensayo bibliográfico mexicano del siglo XVII. $2^{a}$ ed. México: Imprenta del Museo Nacional, 1899.

Pedraza Gracia, Manuel, Yolanda Clemente San Román y Fermín de los Reyes Gómez. El libro antiguo. Madrid: Editorial Síntesis, 2004.

Palau y Dulcet, Antonio. Manual del librero bispano-americano: bibliografía general española e bispano-americana: desde la invención de la imprenta hasta nuestros tiempos, con el valor comercial de los impresos descritos. 2da ed. Barcelona, España: Librería Anticuaria de Palau, 1948-1977

Perales Ojeda, Alicia. La cultura bibliográfica en México. México: UNAM, 2002.

Reglas de catalogación: edición nuevamente revisada. Madrid: Ministerio de Educación, Cultura y Deporte. Dirección General del Libro, Archivos y Bibliotecas: Boletín Oficial del Estado, 2003

Shaner Dunkin, Paul. How to Catalog a Rare Book. Chicago: American Library Association, 1973.

Simón Diáz, José. La bibliografía: conceptos y aplicaciones. Barcelona: Planeta, 1971

, El libro español antiguo. Madrid: Ollero \& Ramos, 2000.

Simpson Moriarty, Kate. "Descriptive cataloguing" Texto disponible en http://etd.ils.unc.edu:8080/dspace/retrieve/465/katemoriarty. pdf

Standard citation forms for published bibliographies and catalogs used in rare books cataloguing / prepared by Peter M. Van Wingen and Belinda D. Urquiza. 2nd ed. Washington: Library of Congress, 1996.

Tanselle, G. Thomas. "Descriptive bibliography and library cataloguing”. En Studies in Bibliography. Vol. 30 (1977). Texto disponible en http://etext.lib.virginia.edu/bsuva/sb/ [Consulta: Enero de 2005]

Torner Morales, Lucía. "El estudio material del libro antiguo: El análisis de guardas, cantos y planos decorados”. En XVIII Encuentro de Investigadores. Del pensamiento novohispano. Noviembre de 2005.

Torre Villar, Ernesto de la. "El trabajo bibliográfico en México". En Nueva Gaceta Bibliográfica. Nos. 23/24 (julio-diciembre 2003). p.10-16

Torres Ramírez. Isabel de "Los estudios de bibliografía en el último cuarto del siglo XX". En Documentación de las Ciencias de la Información. Vol. 25 (2002). p. 147-165 ¿Qué es la bibliografía?: introducción para estudiantes de Biblioteconomía y Documentación. Granada: Universidad, 1996.

Valton, Emilio. Impresos mexicanos del siglo XVI (incunables americanos) en la Biblioteca Nacional de Mexico, el Museo Nacional y el Archivo General de la Nación. México: UNAM, 1935. 
Wagner Enrique W. Nueva bibliografía mexicana del siglo XVI: suplemento a las bibliografías de Don Joaquín García Icazbalceta, Don José Toribio Medina y Don Nicolás León. México: Editorial Polis, 1940.

\section{ANEXO 1:}

LA IMPRENTA EN ALCALA, 1567

(LA CORUNA). Universitaria (OTERO, n.
202).-UPPSALA. Universiletsbibliothek, Bibliotheca Walleriana (SALLANDFR, $\mathrm{n}$ 9784).-VAlencta Faculad de Medicin D-259. VANCOUVER, Univeristy of Briti

688

Wild, Johann (O.F.M.): Commenta riorum Ioannis Feri in sacrosanctum lesu Christi Evangelium secundum Matthaeum. Libri quatuor. Nunc denu correcti et emendati per F. Michaëlem Medinam ordinis Minonam. Compluti. Excudebat Andreas de Angulo.

Fol. $-*^{8}+5{ }^{5} \mathrm{~A}-\mathrm{Z}^{8} \mathrm{Aa}-\mathrm{Q}{ }^{8} \mathrm{Rr}^{6} .-22 \mathrm{~h}$. I-318 f.-L. red. y curs.; tip. gricga. Erratas en sign: 2 (en lugar de +2 ),
D4 (Dd4), E5 (Ee5), G5 (Gg5), O4 (Oo4), O5 (Oo5)

En blanco el lugar correspondiente a la sign. B2.

Erratas en fol. 13 (en lugar de 12) 189 (191), 103 (203), 105 (205), 108

(208), $244(224), 277(273)$

col $y$ a linea

1r: Portada:

[Flor] COMMENTARIORVM IOANNIS FERI IN SACROSANCTVM IESV CHRISTI EVAN - | GE LIVM SECVNDVM I MAT. THAEVM. | LIBRI QVATVOR. | [Corazoncillo] NVNC DENVO CORRECTI ET [corazoncillo] | emendati per F. Michaclem Medi. nam ordinis Minorum ac / sacre Theologix Magistrum,iussu D. D Ferdinandi | Valdesij Archiepiscop Hispalensis \& per | vniuersam His paniam In- | quistoris generalis.
$A D C A R O L V M$ | Hispaniarum Princi-
pem. | CVM PRIVILEGIO REGIS pem. | CVM PRIVILEGIO REGIS |
824

COMPLVTI| Excudebat Andreas de Angulo. | 1567 7. Esta tassado a tre marauedis el pliego. XIIII., grab. xil. representando crucifixión de Cristo.] $+2 \mathrm{r}$ : Licencia y privilegio reales a faw
de Fr. Miguel de Medina (O.F.M.) por plazo de 6 años. Madrid, 28 Febren 1562.

.2 v: Privilegio para las reinos de la co rona de Aragón por plazo de 10 año Madrid, 28 Febrero 1562

$.3 \mathrm{r}-45 \mathrm{r}$; [Flor] Carolo Hispania rum Principi.F. Michael Medina Or dinis Minorum ac sacrx Theologix
Magister. S.P.D. Magister. S.P.D

. dinis Minorum ac Sacrae Theole a lesu 7 . (Hor In Sacrosanctum Nostri Euantelium secundun Matthreum ipsius autoris Praftio +4 r- 1 v: [Adornol Index locuple tissimus renum et nium in primum Tomum commen tariorum Ioannis Feri in Matthæum, qui duos priores libros continet. [A 2 col.]

92 r-96 r: [Flor] Index lucupletis simus rerum et verborum insig mentariorum Io Tomum Com Mathxum, qui tertium et quartu librum continet. [A 2 col.]

S6 v: En blanco.

f.I r-318 r: Text

f.318 r: Colofón: [Después de finalizat el texto:]

[Flor] Finis commentariorum Ioannis Feri $\mid$ in Euangelistam Matthæum. Compluti, Excudebat Andreas de Angulo. I 567 .
825

Existen ejemp. que llevan incorporadas dos hojas, como es el caso del descrito por Agustín Millares Carlo de la Col. José Rafael Fortique, cuyo contenido es, según se indica. (a) Petición de fray Miguel de Medina al Consejo de la Inquis ción, en el que hace constar que ha biéndose opuesto contra los co mentarios de fray Juan Fero al Evangelio segun San Matco cierta proposiciones, las cuales se habian reconocido como católicas por la Facultad de Teología de la Univer sidad de Salamanca, "no embargan. te la aprouación de las dichas pro. posiciones, por no dar lugar a más calumnias, la mesma facultad, en forma de errata, ha declarado algu un de las dichas proposiciones, de as quales hace presentación, en erratas "se impriman $y$ anden con los dichos comentarios, porque na die pueda en ellos repr, porque na. más que por no resultar prohibido dichos comentarios se devuelvan a sus ducños los cjemplares que se les hubiesen confiscado. b) Resolu ción del Consejo, de la cual da fe el secretario Alonso de Dóriga, Madrid, el 30 de junio de 1569 , ac cediendo en todas sus partes a lo solicitado por Medina. c) Informe del decano de la Facultad de Teo logia salmantina, maestro Francis co Sancho, y de los macstros fray juan de Guevara y Grajar, en ol cual se señalan las "erratas" arriba anunciadas.»
LA IMPRENTA EN ALCALÁ, 156 ?

ANTONIO,N. Nova, 11, p. 141: con título poco exacto tomado de Wadding $y$ que se arrastra en alguna otra referen
cia posterior.-ANTONIO MORENO MAR tin (antes GranaTa). Almeria: |Catálo go, 1986], p. 429, n. 280 |reproduce por W-131-GARCiA, un Cat Col. S. XNA n. 408 y $409 .-$ PALAU, $V$, n. 87.723 - -5 MÓN DIAZ, BLH, XIV, n. 3.964 Y 3.966.-ZAMORA, n. 1.60

Barcriona. Püblica Episcopal (Seminario Conciliar), 226.2.07 Wil-BuRgos. Püblit ca. 1446 (2) y 8806 [mútilo de porta (PAZ-REMON-TORRES, p. 28a).-CAGLIA RI. Universitaria, D.C. 257 (ROMERO Frias, n. 415).-Ciudad Real. Pública,

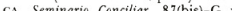
CA. Seminario Conciliar, 87 (bis)-G y
$102-$ C. -Hufsca. Pública, B-38 16059-LEó Seminario 1277 - MA DRID. Nacional, R-30040*; Univ. Complutense. Fac. de Derecho, 700.-MARACalBo Colección José Rafael Fortique (MILLARES Col. J.R. Fortique, n. 37)-ONATE (GUI PUZCOA). Santuarzo de Aranzazu (PP blica, 731 y 732 -SAN LORE ( EsCORIAL MADRID Momasterio 61-IX-13 y 117-IV-31.-SANTANDER. Pública, XVI-3I (GUTtrirrez IGLFSIAS, p 28b).-SANTAGO DE COMPOSTELA (LA CORUNA. PP. Francescanos, 2.12.23; Unt versitaria (BUSTAMANTE, $11,1^{\circ}, \mathrm{n}$ R.57/4/1 y R.68/4/11 WACNEP. ña Portugal, Alcala de Henares n 207).-SORIA. Púbilica, A-3259.-VALEN CIA. Universitaria, Z-2/75.-VALLADOLID Universitaria, 5445,-ZARAGOZA. Universitaria, $\mathrm{H}-2-34$

Este libro ha sido registrado con la metodología propuesta por la tipobibliografía española y corresponde al número $688^{75}$ del catálogo. Como se observa indica una obra de Johann Wild, impresa en Alcalá de Henares por Andreas de Angulo en 1567. El registro es completamente detallado, como es característica metodológica de la bibliografía material. Es interesante anotar que incluso se registran los preliminares de acuerdo con la signatura tipográfica correspondiente. También se hacen anotaciones sobre otros ejemplares que se han revisado y en relación a éstos se establecen las erratas. Tal consideración corresponde a la idea de la "copia ideal", concepto introducido por las aportaciones anglosajonas. 
Por su parte el registro número $147^{76}$ que aquí presentamos, realizado bajo proyecto Fondos Conventuales del el Instituto Nacional de Antropología e Historia (INAH), indica una obra de la autoría de Juan Fero impresa en la misma ciudad y en el mismo año.
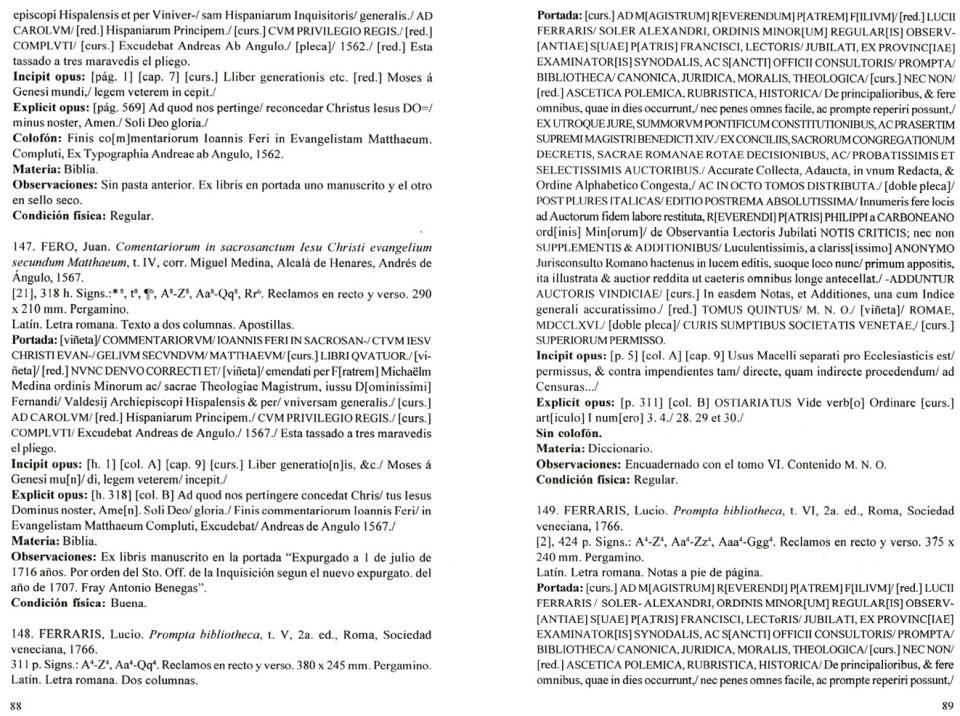

Lamentablemente no contamos con mayores datos para comparar esta representación bibliográfica con la primera presentada, porque el trabajo metodológico del INAH no incluye nada relacionado con las signaturas, los preliminares, la estructura del texto impreso o los repertorios donde el mismo libro ha sido ya registrado. Toda esta información sí está disponible en el registro español, aunque no lo que corresponde al valor histórico de la obra descrita y que sí se incluyó en el registro del INAH.

Finalmente si buscamos la misma obra descrita en catálogos electrónicos disponibles (tanto en la red como en discos compactos), encontraremos otros ejemplares bajo la autoría de Wild ${ }^{77}$ y no de Fero, salvo en aquél que corresponde al mismo trabajo que estamos refiriendo del INAH.

76 Elvia Carreño Velásquez,. Fondo Conventual de la Biblioteca Nacional de Antropología e Historia: Catálogo de la Biblioteca del Convento Grande de San Francisco de la Ciudad de México, V. México: INAH, 2000. p. 88

77 Hemos localizado ejemplares en la Biblioteca Nacional de México (G 226.207 F WIL.C. 1567) y en la Biblioteca Universitaria de Sassan-Sassari en Italia (IT/ICCU/CAGE/022225), no registrados en las instituciones que indica Julián Martín Abad en su registro. Efectivamente para que sea completa esta revisión se tendría que comparar puntualmente la información de este registro, con el original conservado en la Biblioteca Nacional de Antropología e Historia, el que según las indicaciones históricas fue el utilizado para el registro que se analiza. 
El registro siguiente, realizado aplicando la normativa de la ISBD (A) sólo se compondría de los elementos básicos de una descripción breve (autor, titulo y pie de imprenta) y de la descripción física del registro trasladado a nuestra comprensión moderna, es decir, indicando solamente el formato y las páginas de la estructura. Los demás datos, siguiendo esta normativa, corresponden al área de las notas y, por tanto, son de carácter optativo según el criterio establecido en la catalogación de una biblioteca.

\section{Descripción normalizada ISBD (A)}

TORRES, Pedro de (S.I.)

Excelencias de S. Joseph, varon divino, patriarca grande, esposo pvrissimo de la madre de Dios, y altísimo padre adoptivo del hijo de Dios... / el P. Pedro de Torres... Con licencia en Sevilla: por los Herederos de Thomas Lopez de Haro, 1710.

$4^{\circ}[24], 1208$ p., [34]

Notas:

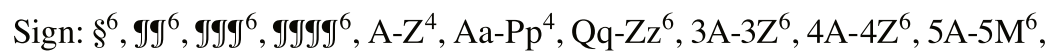
$5 \mathrm{~N}^{5}, \boldsymbol{I}-5 \mathbb{J}^{6}, 6 \mathfrak{J}^{4} .^{78}$

Port. con orla tipográfica y a doble tinta

Marca de Fuego en los tres Cantos del Colegio Apostólico de San Francisco de Pachuca (Marca identificada como de Balvanera. Salas: p. 49). Sellos de tinta en el interior del "Colegio Católico del Sagrado Corazón de Jesús para Instrucción primaria, secundaria y preparatoria por el Pbro. Jesús Espinosa y Labastida".

An. ms. de propiedad en portadilla "Es de la Librería del Colegio App. De N.P.S. Fran.co de Pachuca: pusolo el Herm.o Sector Fr. Juan Zuride siendo Guardian de dho Colegio. Año de 1746" y en pag. 235: "Del Bachiller Don Joseph de Tembra y Zémanes"; An. ms. de compra: "Del Bachiller Don Joseph Xavier Tembra y Zémanes comprado en México por 5 pesos a 13 de mayo de 1741 ".

Encuadernación de pergamino con titulo pintado en el lomo.

78 Cabe recordar que el número que aparece a la izquierda de las signaturas corresponde a las veces que se ha utilizado el símbolo o la letra y, el número a la derecha al total de hojas existentes en un cuadernillo. Este último es preferible indicarlo en superíndice. Existen diversas propuestas para registrar las signaturas, pero podemos dividir estas tendencias entre registrarlas de forma completa o abreviada. En este ejemplo se ha utilizado esta última tendencia. 
EC: Regular con hojas oxidadas y lomo desprendido

Error en signatura del primer cuadernillo, se repite $\$ 3$; y en el segundo cuadernillo, es $\$ \S 3$ y debe ser $\$$ J3 Error en paginación: pasa del número 89 al 100, pero coincide el reclamo y la numeración de párrafos; del 105 al 96 y coincide la información; del 119 al 220 y coincide información; de 277 a 276, y a 279 y coincide información; de 764 a 767, es 1064 y debe ser 1074 Doble columna y apostillas en el texto.

Biblioteca Eusebio Francisco Kino 017316

Palau y Dulcet (1971), 23, p. 413

\section{ANEXO 3:}

Presentamos a continuación una descripción elaborada bajo nuestra propuesta metodológica, para que pueda observarse cómo se puede ver reflejado el valor cultural de un libro en una representación bibliográfica:

\section{Descripción acorde con la metodología de la bibliografía material}

Nuñez, Antonio.

Exercicios espirituales de San Ignacio acomodados a el estado y profesión religiosa de las señoras vírgenes, esposas de Cristo... Con licencia en México: por los Herederos de la Viuda de Bernardo Calderón, 1695.

\section{EXERCICIOS / ESPIRITUALES / DE SAN IGNACIO / ACOMODADOS}

A EL ESTADO, Y / Profe $\iint i o n R e l i g i o \int a$ de las Señoras Virge- / [taco xil.] nes, ESposas de Christo; [taco xil.] / INSTRUIDO / Con un Diario, breve, pero fuficiente de todos / los exercicios cotidianos para que fe empiezen / à exercitar. / [taco xil.] (DISPUESTO) [taco xil.] / I Por el P. PREFECTO de la Congregación de / la Puriffima fundada con Autoridad Apoftolica en / el Colegio Máximo de SAN PEDRO Y SAN PABLO / de la Compañia de IESUS de efta Corte. / † [taco xil.] (Y) [taco xil] † / Dedicados à las mifmas Señoras Religiofas Vírgenes Efpofas de Chrifto. / [Floron] / [Filete] / Con licencia en Mexico por los Herederos de la Viuda / de Bernardo Calderon Año de 1695.

8; (150mm); [J]5, A-I4, J-Z8, Aa-Ee8, F. [5], 196 fol. [2]. RC. 
h.1r.: $\quad$ Portada

h.1v: $\quad$ En blanco.

h.2r.- Dedicatoria

h.3r.:

h.3v.: Parecer del P. Francisco de Vera, jesuita. México, Colegio Maximo de San Pedro y San Pablo de la Compañía de Jesús, 4 de junio de 1694.

h.4r.: $\quad$ Parecer del P. Joaquín de Robles, jesuita. México, Colegio Máximo de San Pedro y San Pablo de la Compañía de Jesús, 29 de mayo de 1694.

h.4v.: $\quad$ Licencia del Provincial. Diego de Almonazir. México, 22 de Mayo de 1694.

h.5r.: $\quad$ Erratas

Fol. 1- Texto de la obra.

196:

h.1r.-2v.: Tabla índice de las cosas que se contienen.

Notas:

An. ms. en portada tachada.

Sellos de tinta en guarda anterior: "JHS Santa Brigida R.” y "CE San Javier", en portada: "JHS Santa Brigida R.", "JHS Biblioteca Casa Iñueo" y otro no identificado en forma triangular.

Encuadernación de piel con guarda anterior pintada a mano con decoración dorada en el lomo y cantos en rojo.

EC: Bueno con las hojas ligeramente oxidadas, tapa anterior desgastada en esquina inferior izquierda

Error en foliación, es y debe ser: 94-93, 164-194. Se repite dos veces el folio162 y 173.

31 líneas de caja de texto ( 33 con paginación y reclamo)

Biblioteca Eusebio Francisco Kino 050623

Medina, J.T. México 1612

Palau y Dulcet ( $2^{\mathrm{a}}$ ed), p. 108 